\title{
Phytochemical analysis, antioxidant, and antimutagenic potentials of Greeniopsis sibuyanensis Elmer
}

\author{
Gina C. Castro ${ }^{* 1,2}$, Grecebio Jonathan D. Alejandro ${ }^{1,3,4}$, \\ Maria Cristina R. Ramos ${ }^{1,3,4}$, E Mafel C. Ysrael ${ }^{1,2,4}$ \\ ${ }^{1}$ The Graduate School; ${ }^{2}$ Faculty of Pharmacy; ${ }^{3}$ Research Center for the Natural and Applied Sciences; \\ ${ }^{4}$ College of Science, University of Santo Tomas, España Boulevard, 1015 Manila, PHILIPPINES
}

\begin{abstract}
Greeniopsis Merr. is one of the poorly known endemic genera of the Philippine Rubiaceae. There is currently little published information on the phytochemistry and biological activities of Greeniopsis species, while important biological activities have been documented for several species of its sister-genus, Ixora L. This study aimed to screen for the presence of major chemical constituents and investigate the antioxidant and antimutagenic potentials of the methanolic leaf extract of Greeniopsis sibuyanensis Elmer. Standard phytochemical screening methods determined the class of plant constituents. The DPPH (2,2-diphenyl-1picryhydrazyl) radical scavenging and the lipid peroxidation inhibition on $\beta$-carotene linoleate model system ( $\beta$-CLAMS) assays tested the antioxidant activities of the extract against $\alpha$ Tocopherol. The SOS-red fluorescent protein bioassay system (SOS-RFP) measured the anti-mutagenic activity of the extract. Phytochemical screening confirmed the presence of alkaloids, steroids, terpenoids, flavonoids, saponins, and tannins. Total phenolic content (TPC) and total flavonoid content (TFC) were found to be $20.06 \mathrm{mg}$ gallic acid equivalents and $4.29 \mathrm{mg}$ quercetin equivalents per gram crude extract, respectively. The $\mathrm{EC}_{50}$ values in the DPPH radical scavenging assay was $42.40 \mu \mathrm{g} / \mathrm{mL}$ for $\alpha$-Tocopherol, and $650.72 \mu \mathrm{g} / \mathrm{mL}$ for the crude extract. The antioxidant activity based on lipid peroxidation inhibition in the $\beta$ CLAMS was found to be $76.84 \%$ and $22.20 \%$ for $\alpha$-Tocopherol (1000 ppm) and crude extract (2500 ppm), respectively. The crude extract was non-mutagenic in the SOS-RFP. It was antimutagenic against mitomycin C-induced damage with an $\mathrm{IC}_{50}$ of $174.84 \mathrm{ppm}$. The preliminary data on the secondary metabolites of $G$. sibuyanensis and the observed antioxidant and anti-mutagenic properties may lead to further chemical and biological investigation for its utility to health and wellness.
\end{abstract}

Keywords: antimutagenic, antioxidant, Greeniopsis, Philippine endemic, SOS-RFP assay

\section{INTRODUCTION}

Rubiaceae is the fourth largest family of flowering plants worldwide [1]. It is the plant

*To whom correspondence should be addressed: gnacastro2006@gmail.com family from which important medicinal alkaloids like caffeine (Coffea L.) and quinine (Cinchona L.) are derived. The Philippine Rubiaceae comprises about 80 genera, and one of the Rubiaceae genera endemic to the Philippines is Greeniopsis Merr. [2]. 
The genus Greeniopsis is reported to have six species mainly distributed in the eastern regions of the Philippines [3]. A phylogenetic study on Greeniopsis has established the placement of the genus in subfamily Ixoroideae and tribe Aleisanthieae. It also resolved Ixora L. as a sister-genus of the tribe Aleisanthieae [4].

This study focused on Greeniopsis sibuyanensis Elmer, a species restricted to Sibuyan Islands in the Visayas. It is one of the species in subclade $\mathrm{A}$, and it was previously known as a synonymy of Greeniopsis multiflora Merr., which is species in subclade B. However, a recent study using molecular (cpDNA markers) and morphological data recognized $G$. sibuyanensis and $G$. multiflora as separate distinct species [4].

In this study, a preliminary phytochemical profile was established, and the antioxidant and antimutagenic properties of the methanolic leaf extract of G. sibuyanensis were investigated. Scientific literature search revealed scarce published information on the phytochemical composition or biological activities of Greeniopsis species. Due to the phylogenetic relationship of Greenioposis species to Ixora species, there is a significant probability that $G$. sibuyanensis will exhibit similar biological activities as the Ixora species, such as freeradical scavenging [5], antimicrobial [6], anti-inflammatory [7], pro-healing [8] and antitumor properties $[9,10]$. To our knowledge, no report has been published on the phytochemistry, anti-oxidant and anti-mutagenic activity of $G$. sibuyanensis.

\section{Materials AND methods}

\section{Collection and preparation of plant material}

Fresh leaves of G. sibuyanensis were collected from Sitio Logdeck, Magdiwang, Romblon. This was done in coordination with Sibuyan Substation and Protected Area Superintendent of Mt. Giting-Giting Natural Park, and with permission from DENR Region IV-B MIMAROPA Office (Wildlife Gratuitous Permit No. 2009-01). The plant material was identified and authenticated by G.J.D. Alejandro, a Rubiaceae specialist, and deposited at the University of Santo Tomas Herbarium (USTH5473).

The collected leaves were cleaned and air-dried at room temperature, cut into small pieces and pulverized in a Wiley mill. The powdered leaf sample was extracted with absolute methanol by exhaustive cold percolation. The extract was concentrated under reduced pressure at $45^{\circ} \mathrm{C}$ in a rotary evaporator (Heidolph Laborota 4001) until a syrupy mass, known as crude $G$. sibuyanensis extract (GSE) was obtained. The crude methanolic leaf extract was stored in a refrigerator until analyzed. The crude extract is a greenish black semi-solid with herbal aroma. The average percentage yield was $14.80 \pm 0.29 \%$ $\mathrm{w} / \mathrm{w}(n=3)$.

\section{Phytochemical screening for secondary plant metabolites}

The presence of major groups of secondary plant constituents was determined using standard methods [11]. Two replicates were performed for each test.

Test for alkaloids. A portion of crude extract was treated with $5 \mathrm{~mL}$ of $2 \mathrm{M} \mathrm{HCl}$, and heated for $5 \mathrm{~min}$. After cooling, $0.5 \mathrm{~g} \mathrm{NaCl}$ was added with stirring. After filtering, the residue was washed and filtrate brought to final volume of $5 \mathrm{~mL}$ with $2 \mathrm{M} \mathrm{HCl}$. Few drops of Dragendorff's reagent was added to $1 \mathrm{~mL}$ of the filtrate. An orange precipitate indicated the presence of alkaloids.

Test for steroids (unsaturated). The crude extract was defatted by treatment with portions of hexane and water $(2: 1 \mathrm{v} / \mathrm{v})$ until most of the colored pigments have been removed. Residual hexane was removed by heating over water bath. The aqueous layer was treated with $10 \mathrm{~mL}$ 
dichloromethane and allowed to stand. The lower dichloromethane layer was dried by passing through anhydrous $\mathrm{Na}_{2} \mathrm{SO}_{4}$ placed over dry filter paper in a funnel. One portion of the filtrate was used as control. The second portion was treated with three drops of acetic acid and one drop of concentrated $\mathrm{H}_{2} \mathrm{SO}_{4}$ and allowed to stand for 1 $\mathrm{h}$. The development of colors ranging from blue to green, red, pink, purple or violet indicated the presence of steroid/triterpenoid skeleton.

Test for terpenoids. A portion of the crude extract was dissolved in $3 \mathrm{~mL}$ water and treated with $10 \mathrm{~mL} n$-butanol. The mixture was shaken, then allowed to stand. The $n$-butanol layer was evaporated to $1 \mathrm{~mL}$ volume and spotted on thinlayer chromatography (TLC) plate. The plate was developed in chloroform and sprayed with vanillin-sulfuric acid. After warming over hot plate, the plate was observed for red-violet or purple spots at $R_{\mathrm{F}}$ of $60-70$ which signified presence of terpenoids.

Test for flavonoids. A portion of crude extract was defatted with $9 \mathrm{~mL}$ hexane and water (2:1). The aqueous layer was diluted with $10 \mathrm{~mL}$ of $80 \%$ ethyl alcohol and filtered. One portion of the filtrate was used as control. The second portion was treated with $0.5 \mathrm{~mL}$ concentrated $\mathrm{HCl}$. A few pieces of magnesium turnings were added and the mixture observed for color changes. The mixture was shaken with an equal volume of water and $1 \mathrm{~mL}$ of octyl alcohol. Colors ranging from orange to red, crimson and magenta, and green or blue indicated the presence of $\gamma$-benzopyrone nucleus.

Test for saponins. A portion of crude extract was mixed with distilled water and shaken vigorously for $30 \mathrm{sec}$. A honeycomb froth greater than $2 \mathrm{~cm}$ height from the surface of the liquid that persists after 10 min indicated the presence of saponins.

Test for tannins. The crude extract was extracted with $20 \mathrm{~mL}$ of hot distilled water and treated with five drops of $10 \% \mathrm{NaCl}$ solution. After filtering, a few drops of $0.03 \% \mathrm{FeCl}_{3}$ solution were added to the filtrate. The appearance of a brownish green color indicated the presence of condensed tannins, while a blue-black color confirmed the presence of hydrolysable tannins.

\section{Quantitative analysis of phytochemicals}

Total phenolic content. The TPC was determined following a previously reported method [12]. Folin-Ciocalteau's phenol reagent $(1.5 \mathrm{~mL}, 10 \%$ $\mathrm{v} / \mathrm{v})$ and $\mathrm{Na}_{2} \mathrm{CO}_{3}(1.2 \mathrm{~mL}, 7.5 \% \mathrm{w} / \mathrm{v})$ were added to $0.3 \mathrm{~mL}$ of crude methanolic leaf extract (500 ppm in dimethylsulfoxide). The reaction mixture was thoroughly mixed and was incubated in the dark for $30 \mathrm{~min}$. The absorbance of the reaction mixture was measured at $765 \mathrm{~nm}$ (Genesys $10 \quad$ Spectrophotometer). Dimethylsulfoxide (DMSO) was used for baseline correction. Three independent measurements were performed and results averaged.

TPC was calculated using a calibration curve for gallic acid (10-40 ppm). The result was expressed as milligram gallic acid equivalents (GAE) per gram crude methanolic leaf extract.

Total flavonoid content. The TFC was determined following the procedure used by Chew, Goh, and Lim with minor modifications [12]. The crude methanolic leaf extract $(0.5 \mathrm{~mL}, 2000 \mathrm{ppm}$ in DMSO) was mixed with methanol $(1.5 \mathrm{~mL})$, aluminum chloride $(0.1 \mathrm{~mL}, 10 \% \mathrm{w} / \mathrm{v})$, potassium acetate $(0.1 \mathrm{~mL}, 1 \mathrm{M})$, and $2.8 \mathrm{~mL}$ water. The reaction mixture was allowed to incubate for $30 \mathrm{~min}$ at room temperature before the absorbance was taken at $435 \mathrm{~nm}$ (Genesys 10 Spectrophotometer). DMSO was used for baseline correction. Blank determinations were performed using water $(0.1 \mathrm{~mL})$ in place of the aluminum chloride solution. Three independent measurements were performed and results averaged. 
TFC was calculated using a calibration curve for quercetin (5-30ppm). The result was expressed as milligram quercetin (QE) equivalents per gram crude methanolic leaf extract.

\section{Antioxidant activity assay}

\section{DPPH free-radical scavenging assay. The DPPH} radical scavenging activity was measured following a previously reported method with minor modifications [12]. Solutions containing varying concentrations of the crude leaf extract (500 ppm, 1000 ppm, 1500 ppm, and 2000 ppm in DMSO) and $\alpha$-Tocopherol (20 ppm, $30 \mathrm{ppm}$, $40 \mathrm{ppm}$, and 50ppm in methanol) were prepared. DPPH (2 mL, $0.15 \mathrm{mM}$ in methanol) was added to $1 \mathrm{~mL}$ of the different dilutions of the crude leaf extract and $\alpha$-Tocopherol. The reaction mixture was allowed to incubate in the dark for 30 min before the absorbance was taken at 517 nm (Genesys 10 Spectrophotometer). DMSO and methanol were used in baseline correction for the crude leaf extract and $\alpha$-Tocopherol, respectively. Blank determinations were performed for the crude leaf extract using methanol (2 mL) in place of DPPH solution.

Three independent measurements were performed and results averaged. Scavenging activity for $\alpha$-Tocopherol was calculated using the following formula:

$\%$ Scavenging effect $=A_{\text {methanol }}-A_{\text {std }} / A_{\text {methanol }} \times 100$

where $A_{\text {methanol }}$ is the mean absorbance of methanol and $\mathrm{A}_{\mathrm{Std}}$ is the mean absorbance of particular concentrations of $\alpha$-Tocopherol solution. While scavenging activity for the crude extract was calculated using the following formula:

$$
\begin{aligned}
\% \text { Scavenging effect } & =A_{D M S O}-\left(A_{S A}-A_{S B}\right) / A_{D M S O} \\
& \times 100
\end{aligned}
$$

where $A_{\text {DMSO }}$ is the mean absorbance of DMSO, $\mathrm{A}_{\mathrm{SA}}$ is the mean absorbance of particular concentrations of the crude extract solution in the actual determination and $\mathrm{A}_{\mathrm{SB}}$ is the mean absorbance of particular concentrations of the crude extract in the blank determination.

The antioxidant activity of the crude extract was expressed as $\mathrm{EC}_{50}$ (effective concentration) or the concentration (in $\mu \mathrm{g} / \mathrm{mL}$ ) of the crude extract required to inhibit the formation of DPPH radicals by $50 \%$.

Lipid peroxidation inhibition assay by $\boldsymbol{\beta}$ CLAMS. The antioxidant activity in terms of lipid peroxidation was determined following the procedure used by Othman and colleagues with minor modifications [13]. $\beta$-carotene $(0.2 \mathrm{mg}$ in $\left.1 \mathrm{~mL} \mathrm{CHCl}_{3}\right)$, linoleic acid $(0.02 \mathrm{~mL})$ and Tween $20(0.2 \mathrm{~mL})$ were transferred into a roundbottomed flask. The mixture was added to $0.2 \mathrm{~mL}$ of crude methanolic leaf extract (2500 ppm in DMSO). Chloroform was removed at $40^{\circ} \mathrm{C}$ under vacuum at reduced pressure using a rotary evaporator (Buchi Rotavapor R-200). Following evaporation, $50 \mathrm{~mL}$ of distilled water was added to the contents in the round-bottomed flask and the mixture was shaken vigorously to form an emulsion. Two milliliter aliquots of the emulsion were pipetted into test tubes and immediately placed in a water bath at $50^{\circ} \mathrm{C}$. The absorbance was read at $20 \mathrm{~min}$ intervals for $2 \mathrm{~h}$ at $470 \mathrm{~nm}$, using a Genesys 10 Spectrophotometer. Same procedure was performed using $\alpha$-Tocopherol (1000 ppm in DMSO) and DMSO as standard and solvent control, respectively.

Three independent measurements were performed for the sample extract, standard and solvent control. Degradation rate (DR) was calculated according to first-order kinetics, using the following equation:

$$
D R=\ln (A o / A t) / t
$$

where $\ln$ is the natural $\log , A o$ is the initial absorbance at time $0, A t$ is the absorbance at 20, 
$40,60,80,100$ or $120 \mathrm{~min}$ and $t$ is the initial absorbance at time 0 .

Antioxidant activity (AA) was expressed as percent of inhibition relative to the control, using the following formula:

$$
A A=D R_{\text {Control }}-D R_{\text {Test }} / D R_{\text {Control }} \times 100
$$

where $\mathrm{DR}_{\text {control }}$ is the DR of DMSO at $120 \mathrm{~min}$ and $\mathrm{DR}_{\text {test }}$ is the DR of the crude extract or $\alpha$ Tocopherol standard at $120 \mathrm{~min}$.

\section{Mutagenic activity assay}

Mutagenicity testing by SOS-RFP assay. The SOS-RFP assay was performed according to a previously reported method with minor modifications [14]. A $400 \mu \mathrm{L}$ aliquot of glycerolcultured Escherichia coli RS4U was added to 20 mL Luria-Bertani (LB) medium containing $100 \mu \mathrm{g} / \mathrm{mL}$ Ampicillin sodium salt. The cells were grown for $6 \mathrm{~h}$ at $32^{\circ} \mathrm{C}$ with $250 \mathrm{rpm}$ shaking rate in a thermoshaker (MRC Orbital Shaker Incubator). One (1) $\mathrm{mL}$ aliquot of the cell culture was transferred to $40 \mathrm{~mL}$ fresh $\mathrm{LB}$ medium. The cells were grown for another $2 \mathrm{~h}$ under the same conditions.

Four (4) mL aliquots of pre-cultured cells were placed in separate vials. Test solutions to provide varying concentrations of the crude extract (100 ppm, 200 ppm, 300 ppm, 400 ppm, and 500 ppm in DMSO), $\alpha$-Tocopherol (500 ppm in DMSO), Mitomycin C (MMC) (0.07 ppm) or Nalidixic acid (NA) $(0.70 \mathrm{ppm})$ were added to the pre-cultured cells, and sufficient LB medium used to complete $5 \mathrm{~mL}$ in each vial. DMSO served as solvent control. Test samples were incubated at $32^{\circ} \mathrm{C}$ with $250 \mathrm{rpm}$ shaking rate in a thermoshaker for $20 \mathrm{~h}$. One (1) mL aliquot of cell suspension from each vial was centrifuged for 5 min at 5000 rpm (Hettich Zentrifugen Mikro 220R). Cells were collected and washed with $1 \mathrm{~mL}$ of $0.9 \% \mathrm{NaCl}$ solution. The cell suspension was centrifuged at $5000 \mathrm{rpm}$ for another $3 \mathrm{~min}$.
Cells were collected and resuspended in $1 \mathrm{~mL}$ of $0.9 \% \mathrm{NaCl}$ solution. Sample solutions were subjected to vortex. Fluorescence at $550 \mathrm{~nm}$ (excitation) / 580 nm (emission) (Hitachi F-4500 Fluorescence Spectrophotometer) and optical density (OD) at $600 \mathrm{~nm}$ (Perkin-Elmer Lambda 35 UV-Vis Spectrometer) were determined.

Three independent measurements were performed and the results were averaged. The relative fluorescent unit (RFU) was obtained by dividing the fluorescence with OD value.

Antimutagenicity testing by SOS-RFP assay. Four (4) mL aliquots of pre-cultured cells were placed in separate vials. Each vial was treated with either Mitomycin-C (MMC 0.07 ppm) or Nalidixic Acid (NA 0.70 ppm), and test solutions to provide varying concentrations of the crude extract (100 ppm, 200 ppm, 300 ppm, 400 ppm, and $500 \mathrm{ppm}$ in DMSO) and $\alpha$-Tocopherol (500 ppm in DMSO). Sufficient LB medium was used to complete $5 \mathrm{~mL}$ in each vial. DMSO served as solvent control. Test samples were incubated and collected in the same manner as in the Mutagenicity Testing. Fluorescence at $550 \mathrm{~nm}$ (excitation) / $580 \mathrm{~nm}$ (emission) and optical density (OD) at $600 \mathrm{~nm}$ were determined.

Measurements were performed in triplicates and results averaged. The RFU was obtained by dividing the fluorescence with OD value. Antimutagenic activity (AMA) was calculated using the following formula:

$$
A M A=R F U_{\text {Control }}-R F U_{\text {Test }} / R F U_{\text {Control }} \times 100
$$

where $\mathrm{RFU}_{\text {control }}$ is the RFU of DMSO and $\mathrm{RFU}_{\text {test }}$ is the RFU of the crude extract or $\alpha$-Tocopherol standard.

The antimutagenic activity of the crude extract was expressed as IC $_{50}$ (inhibitory concentration) or the concentration (in $\mathrm{mg} / \mathrm{L}$ or $\mathrm{ppm}$ ) of the crude extract that gave a response halfway between the baseline and maximum response. 


\section{RESUlTS AND DISCUSSION}

Phytochemical composition. Phytochemical screening revealed that the crude methanolic leaf extract of $G$. sibuyanensis contained several bioactive compounds (Table 1). Similar secondary metabolites have been detected in $G$. multiflora [15]. The presence of these bioactive compounds has been reported for several Ixora species with documented medicinal properties, confirming the possibility of significant pharmacological activity of G. sibuyanensis [16].

The TPC and TFC of the crude extract based on net mean absorbance readings, are presented in Table 2. These constituents are associated with antioxidant property of the extract.

Anti-oxidant activity. The anti-oxidant activity of the crude extract was measured using the DPPH free radical scavenging assay and the $\beta$ CLAMS lipid peroxidation inhibition assay. The DPPH assay evaluates antioxidant properties through the discoloration of DPPH due to freeradical scavenging action of the antioxidant [13]. The lipid peroxidation inhibition assay is based on the decrease in the bleaching of $\beta$-carotene due to linoleic acid oxidation. It considers the partition in organized media and antioxidant mechanisms other than radical scavenging. It also takes into account the inhibition of oxidative enzymes in a micro heterogenous system; thus, the results are more indicative of antioxidant action in biological systems [17].

Table 1. Phytochemical composition of the methanolic extract of $G$. sibuyanensis leaves

\begin{tabular}{l|c}
\hline \multicolumn{1}{c|}{ Phytochemicals } & Inference \\
\hline Alkaloids & + \\
Steroids (Unsaturated) & + \\
Terpenoids & + \\
Flavonoids & + \\
Saponins & + \\
Condensed tannins & + \\
\hline
\end{tabular}

(+) Presence; (-) Absence
In the DPPH assay, the absorbance due to the $\mathrm{DPPH}$ free radical was decreased in the presence of the extract. This response was concentrationdependent. The $\mathrm{EC}_{50}$ value for the crude extract was found to be $650.72 \mu \mathrm{g} / \mathrm{mL}$, which indicated a lower antioxidant activity compared to a $\alpha$ Tocopherol standard $\left(\mathrm{EC}_{50}=42.40 \mu \mathrm{g} / \mathrm{mL}\right)$. The free-radical scavenging activity of the extract can be attributed to the phenolic constituents such as flavonoids and tannins.

In the lipid peroxidation inhibition assay, the extract inhibited the bleaching of $\beta$-carotene by the hydroperoxides produced from linoleic acid. The mean DR increased with time, following a first-order kinetics behavior (Fig. 1). The antioxidant activity of the crude extract (2500 ppm) was found to be $22.20 \%$, this was lower than $76.84 \%$ antioxidant activity of the $\alpha$ Tocopherol control (1000 ppm) which is a pure compound.

Anti-mutagenic activity. Prior to the testing for anti-mutagenic activity, mutagenicity testing was performed to determine any mutagenic or toxic effect of the crude extract on the test $E$. coli strain used in the SOS-RFP assay. Mutagenicity testing was carried out using the SOS-RFP assay, which is based on the detection of mutation in a modified strain E. coli RS4U, through the fluorescence of the RFP protein [14].

Table 2. Total phenolic and total flavonoid content of the methanolic extract of $G$. sibuyanensis leaves per gram of crude extract

\begin{tabular}{l|c}
\hline & $\begin{array}{c}\text { Mean } \\
\text { (Values at 95\% CI) }\end{array}$ \\
\hline $\begin{array}{l}\text { Total phenolic content } \\
\text { (mg gallic acid equivalents) }\end{array}$ & $20.06(18.26-20.66)$ \\
\hline $\begin{array}{l}\text { Total flavonoid content } \\
\text { (mg quercetin equivalents) }\end{array}$ & $4.29(4.195-4.385)$ \\
\hline
\end{tabular}




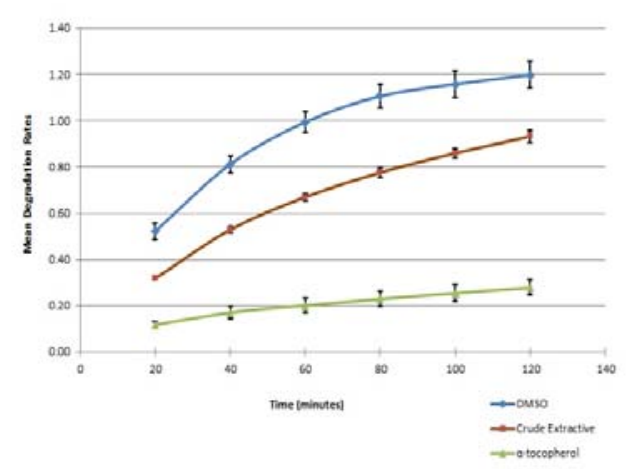

Figure 1. Plot of the mean degradation rates for the test solutions at different time points in the $\beta$-CLAMS assay, expressed as the average of three independent trials.

Figure 2 shows the fluorescence, expressed in RFU, generated by different concentrations of the crude extract, by known mutagens, such as mitomycin C (MMC) and nalidixic acid (NA), tocopherol, and by a DMSO solvent control. Significant difference was found between the mean RFU of the eight treatments using SingleFactor ANOVA $(p<0.001)$. However, Duncan's multiple range test indicated that the mean RFU of the different concentrations of the crude extract (GSE) did not differ significantly from the mean RFU of the solvent control. These results of significance tests indicated that the mean RFU, all test concentrations of the crude extract were non-mutagenic.

Since crude extract has been established to be non-mutagenic, its anti-mutagenic activity of against MMC- and NA-induced mutagenicity was subsequently determined, this time adding the extract to genotoxicant treated cells. A decrease in the intensity of the fluorescence produced by genotoxicant-treated cells is an indication that the test sample was able to inhibit the adverse effect of the genotoxicant on the microorganism [14]. Figure 3 shows that there is generally a dose-dependent decrease in the RFU values for the crude extract. The $\mathrm{IC}_{50}$ value of

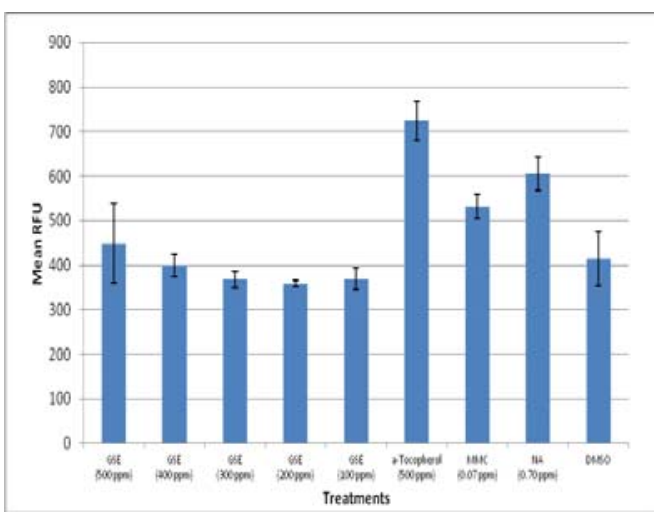

Figure 2. Mutagenicity response of E. coli RS4U in the SOS-RFP assay obtained using GSE, $\alpha-$ Tocopherol, MMC, and NA expressed as RFU. Values expressed as mean of three independent measurements in triplicates.

the crude extract was found to be $174.84 \mathrm{ppm}$ against MMC-induced mutagenicity. Based on the inconsistent results obtained, the crude extract was considered to be ineffective against NA-induced mutagenicity. The crude extract appears to inhibit or reduce the DNA damaging effects of alkylating agent like MMC, but does not protect from damaging effects caused by interventions in DNA replication as observed from the results of GSE with NA.

\section{Conclusion}

This study provides evidence-based support for the potential medicinal utilities of Greeniopsis species. The secondary metabolites found in the methanolic leaf extract are known to be responsible for important biological activities, and these have been examined for in its sister-genus, Ixora. The antioxidant and antimutagenic activities exhibited by the crude extract may be important leads for applications in the management of chronic diseases associated with oxidative stress conditions. 


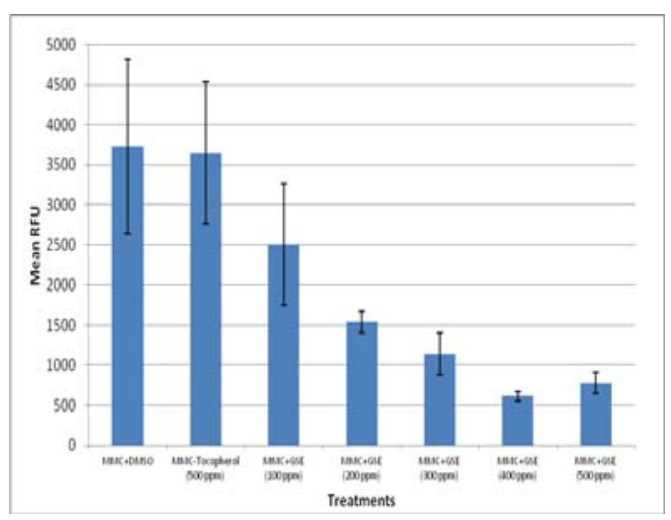

Figure 3. The comparative mutagenicity response of MMC-treated E. coli RS4U in the SOS-RFP assay to GSE, $\alpha$-Tocopherol, and DMSO expressed as RFU. Values expressed as mean of three independent measurements in triplicates.

\section{ACKNOWLEDGMENT}

The authors would like to acknowledge the funding support provided by the Department of Science and Technology - Philippine Council of Health Research and Development (DOSTPCHRD).

\section{REFERENCES}

[1] Robbrecht E. Tropical Woody Rubiaceae. Opera Botanica Belgica 1988, 1:177-196.

[2] Alejandro GJ \& Liede S. The Philippine Rubiaceae Genera: Updated Synopsis in INTKEY Databases of the DELTA System. BLUMEA 2003, 48:261277.

[3] Madulid DA. The Endemic Genera of Flowering Plants in the Philippines. Acta Manilana 1991, 39:47-58.

[4] Alejandro GJD, Meve U, Uy M, Mouly A, Thiv M, \& Liede-Schumann S. Molecular support of the classification of Greeniopsis Merr. in Aleisanthieae (Rubiaceae), with a revision of the genus. Taxon 2010, 59(5):1547-1564.

[5] Saha MR, Alam A, Akter R, \& Jahangir R. In-vitro Free Radical Scavenging Activity of Ixora coccinea L. Bangladesh Journal of Pharmacology 2008, 3:90-96.
[6] Annapurna J, Amarnath PVS, Kumar A, Ramakrishna SV, \& Raghavan KV. Antimicrobial Activity of Ixora coccinea leaves. Fitoterapia 2003, 74:291-293.

[7] Ratnasooriya WD, Deraniyagala SA, Galhena G, Liyanage SSP, Bathige SDNK, \& Jayakody JRAC. Anti-inflammatory Activity of the Aqueous Leaf of Ixora coccinea. Pharmaceutical Biology 2005, 43(2):147-152.

[8] Nayak BS, Udupa AL, \& Udupa SL. Effect of Ixora coccinea flowers on Dead Space Wound Healing in Rats. Fitoterapia 1999, 70(3):233-236.

[9] Latha PG \& Panikkar KR. Inhibition of Chemical Carcinogenesis in Mice by Ixora coccinea flowers. Pharmaceutical Biology 2000, 38:(2).

[10] Nair SC, Panikkar B, Akamanchi KG, \& Panikkar KR. Inhibitory Effects of Ixora javanica Extract on Skin Chemical Carcinogenesis in Mice and Its Antitumour Activity. Cancer Lett 1991, 60:253258.

[11] Aguinaldo AM, Espeso EJ, Guevarra BQ, \& Nonato MG. A Guidebook to Plant Screening: Phytochemical and Biological (Rev. Ed). (UST Publishing House, 2005).

[12] Chew YL, Goh JK, \& Lim YY. Assessment of In Vitro Antioxidant Capacity and Polyphenolic Composition of Selected Medicinal Herbs from Leguminosae Family in Peninsular Malaysia. Food Chemistry 2009, 116:13-18.

[13] Othman A, Ismail A, Ghani NA, \& Adenan I. Antioxidant Capacity and Phenolic Content of Cocoa Beans. Food Chemistry 2007, 100:15231530.

[14] Bartolome A, Mandap K, David KJ, Sevilla FIII, \& Villanueva J. SOS-Red Fluorescent Protein (RFP) Bioassay System for Monitoring of Antigenotoxic Activity in Plant Extracts. Biosens Bioelectron 2006, 21:2114-2120.

[15] Karimi RB \& Dedeles GR. Antimicrobial Activity and Preliminary Phytochemistry of Greeniopsis multiflora Elmer (Merr.)(Rubiaceae) Crude Leaf Extract. Transactions of the National Science and Technology, 2015, 37(1):165.

[16] Dontha S, Kamurthy H, \& Mantriprogada R. Phytochemical and Pharmacological Profile of Ixora: A review. International Journal of Pharmaceutical Sciences and Research 2015, 6:567-584.

[17] Chaillou L \& Nazareno M. Bioactivity of Propolis from Santiago del Estero, Argentina, Related to their Chemical Composition. LWT - Food Science and Technology 2009, 42:1422-1427. 